\title{
Investigación El tiempo expuesto
}

Dominique Païni

Director de Desarrollo Cultural. Centro Pompidou (Paris)

\section{Resumen}

Ante el incuestionable valor del cine como patrimonio cultural, Païni plantea en este artículo algunas de las claves que ayudan a reflexionar y entender las dificultades y problemáticas existentes en torno a la práctica de conservación y restauración del patrimonio cinematográfico y las instituciones encargadas de su salvaguarda. Para Païni, la consideración patrimonial del arte cinematográfico, así como una excesiva obsesión por proteger la memoria, corre el riesgo de alejar a las peliculas de su destino inicial, metamorfoseando su naturaleza, provocándose lo que él denomina desobramiento, un concepto que pone de relieve la complejidad del proceso al que estamos asistiendo.

\section{La evidencia patrimonial en cuestión}

La noción de patrimonio cinematográfico se ha convertido en una evidencia. Sin embargo, se plantean múltiples interrogantes cuando ésta afecta el arte cinematográfico.

El patrimonio nace de la conjunción de lo admirable y de lo perecedero. Nacido de una protesta contra el desgaste, el sentimiento patrimonial se integró finalmente en el ciclo de la racionalidad y del desgaste. El ejemplo del cine es evidente: los editores de cintas o de DVD (Digital Vídeo Disc) se interesan de ahora en adelante por las viejas bandas y también los canales de la difusión televisiva, de los cuales estaría mal visto quejarse por lo mucho que contribuyen a conocer mejor el trabajo de las filmotecas. Pero estas últimas se cuestionan, ya que desde la aparición de la palabra, y más bien desde su generalización, su trivialidad y su aplicación al cine, el patrimonio aparece como el término provisional de un proceso comenzado desde los origenes del cine.

Desde 1850 a 1908, el cine (incluido el precine) es una curiosidad, una física divertida, aquella de la cual Baudelaire decía que estaba dotada de una moral. El fenakisticope es hallado por un Baudelaire mirón casualmente en las Tuileries. Si bien no le gusta al poeta la fotografía, éste queda deslumbrado por ese aparato de repetidas metamorfosis que reproduce el tiempo como una representación. $Y$ a pesar de que Baudelaire se resiste a ese "movimiento que desplaza las líneas", describe precisamente el aparato como una curiosidad fascinante. Su preocupación es la de salvar la inmovilidad. Estos primeros pasos del cine son los de un juguete $\sin$ futuro.

Entre 1908 y 1950, el cine se ha convertido en una distracción de masa producida por la lógica industrial y justificada por la reconstitución de la fuerza de trabajo del público proletario. Dicha reconstitución, que engendrará más tarde la civilización y la religión del ocio, ¿fue acaso el equivalente del tiempo consagrado en la antigüedad a la devoción religiosa? En ambos casos, se trata de adorar imágenes: los frescos y las pantallas se miran al levantar la mirada.

Entre 1950 y 1968, el cine se ha ganado su clasificación en el apartado del arte. En los años diez y veinte, algunos artistas lo apreciaban precisamente porque no era un arte. Por ese mismo hecho, y paradójicamente, fue promovido por ellos mismos, al rango de "séptimo arte", otro arte en contra de las Bellas Artes. Siendo de ese modo un no-arte, se convierte en el último que cierra todas las demás artes. Los cubistas, los dadaístas, los futuristas, los surrealistas amaron el cine y lo convirtieron en el arte del siglo XX porque era para ellos el golfo de las artes. Para las vanguardias históricas (los artistas) y luego la nueva crítica de los años cincuenta (los autores), el cine es un arte, el arte de ese siglo en el cual el mismo Godard describe en sus Histoire(s) 


\begin{tabular}{|l|}
\hline Investigación \\
El tiempo expuesto \\
Dominique Païni \\
\hline
\end{tabular}
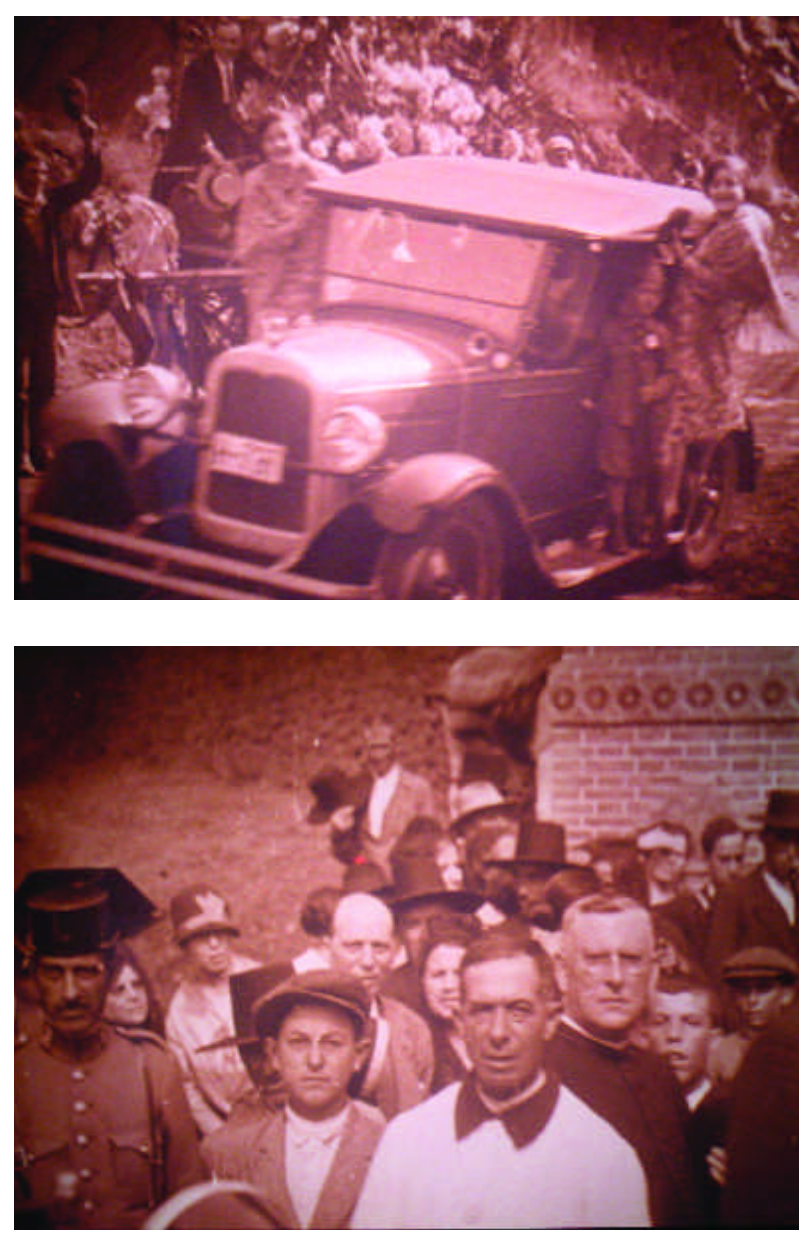

como capaz de todo y que nada había impedido; la guerra, los campos, la bomba. Un arte pues, a la medida de su debilidad.

Entre 1968 y 1990, el cine se convierte en ocio, en cultura. Las capas sociales llamadas "medias", cuyas necesidades de reconstrucción de la fuerza de trabajo son menores, hacen de la cultura una actividad social. El cine se convierte, pues, en cultur ra: las obras de arte cinematográficas están "en peligro" (la televisión las divulga) y las buenas señas se conjugan en pasado (se destruyen las salas de barrios). Su valor sube con su enrarecimiento como cualquier otra materia prima. Se convierten en una especie de "sobre-yo" para la cultura que es un todo - de su influencia sobre las demás artes a la de las estrellas sobre la vida cotidiana. El cine se convierte finalmente en un argumento de venta y en una moda. Se vende cualquier cosa con el imaginario cinematográfico. La cultura de masa, o lo que llamamos el gran público, no se lleva bien con el arte.
Si los gestos fanáticos que destruyen las estatuas se parecen a los gestos que las engendran, lo mismo ocurre para el cine: los gestos que destruyen las películas, gestos que cortan copias enteras, se parecen a los gestos que construyen los tiempos cinematográficos. El montaje es también un asunto de cortes. Pero, de la amnesia engendrada por la destrucción de las copias, hemos pasado a una empresa de anam nesia deliberada y sistemática. Hay que salvarlo todo, conservarlo todo para poder volverse contra todo. Como el monumento a los muertos, la tumba, el cenotafio, el arco del triunfo y el museo, el cine está herido por lo que Aumont denomina el complejo de Orfeo.

Preservarlo todo, conservarlo todo. Se terminaron los olvidos, se terminaron las posibles lagunas en la memoria, se terminaron la melancolía provocada por la pérdida. Se intenta cubrir el pasado vivido y sus huellas depositadas en el presente como se recubrian, sin abstracciones ni reducciones, un territorio y un mapa ¿Cómo meditaremos de ahora en adelante sobre las ruinas, tal como el Bellarmin de Hölderlin en medio de un campo lleno de flores del cual surgen cabezas y miembros de dimensiones ideales, fragmentadas, desgajadas de su destino inicial y, en sentido propio, desgajadas de conjuntos dotados originalmente de significado? Quizás ya no tengamos derecho a decir, como Mary Meerson a la Filmoteca francesa, que tal película será recordada cuando la humanidad se lo merezca... Las carencias, los olvidos, las pérdidas, los pedazos engendraron antiguamente la investigación, la ciencia, la poesía, la escritura ¿Qué serán en el futuro la escritura y el imaginario si el patrimonio obliga a guardarlo todo y a conservarlo todo? ¿Qué escritura, qué imaginación y qué sueños estarán permitidos si ya no falta nada del pasado? ¿Existirá un abuso patrimonial: un segundo mundo paralelo al presente en curso, un inmenso cementerio llamado púdicamente archivos, cuyos contornos se adaptarian al presente que se está gestando? A pesar de las enseñanzas de Bergson, la noción de patrimonio parece ignorar la indivisibilidad del cambio. El patrimonio induce que el pasado es aquello que está abolido y que una misión colectiva debe conservar como tal, al tiempo que instituye una demarcación entre nuestro presente y ese pasado: "Nos creemos entonces obligados a imaginar un aparato cuya función sería grabar las partes del pasado susceptibles de reaparecer en la conciencia" ¿Dicho aparato se Ilama patrimonio?

Curiosidad, ocio, arte, cultura, patrimonio: un proceso sin apenas reflexión que se ha desarrollado sin embargo ¿Podría esto llevarnos a dudar, paradójicamente, de la memoria cuando esta última ya no está activada por la obra de arte que, sin haber recibido la misión ideológica y social, es obra de la memoria? ¿Podemos suponer que cuanto más crezca el patrimonio más se olvidará la obra? Probablemente sea excesivo. Sin embargo, el proceso que va de la curiosidad al patrimonio parece guardar algo de cada una de las etapas descritas. Pero cualquier etapa que va hacia más respeto, más dignidad, más memoria, más conservación en beneficio del arte, borra irremediablemente. 
La memoria no puede evitar la aniquilación: fetichización y des trucción del pasado ¿Se instaura la memoria a costa del arte? ¿Acaso es un proceso de desobramiento? "(...) La palabra obra de arte, la palabra obra, y el de posteridad y de la gloria, y la de cultura, la de creación y de existencia, la de destrucción y de la nada y, para terminar, la palabra de origen, se han ofrecido por turno y se han retirado, pero quizás no borrándose totalmente en cada ocasión, dejando en ese movimiento una pista y un trazo casi imborrable. De ese modo, la obra de arte ha desaparecido, cediendo su lugar a la obra entendida como su propia superación; y la obra a su vez como la afirmación de la obra no produr cida, no puesta en obra, la experiencia del desobramiento; y la idea de modernidad como la idea de una ruptura más profunda indicando el cese de ese todo memorable...".

Las películas conservadas en las filmotecas, las propias filmotecas, con su dispositivo de consulta para restituir la historia del cine como un río, como una panorámica o un travelling retrospectivo, están dotadas de un valor histórico según la expresión del historiador Aloïs Riegl, es decir, un valor documental positivo, objetivo: buscar restituir el estado original de un documento, de un monumento mediante un trabajo de interpretación que intenta deshacerse de las escorias que la han parasitado a lo largo de los tiempos. Esto ha sido el caso de las películas, incluidas aquellas que se consultarán e incluso no se proyectarán ¿Acaso no se dice ya que Internet será la vía de acceso? En cuanto al valor llamado de antigüedad, según ese mismo historiador del arte, es paradójicamente "más moderno", más objetivo, más bien del lado de la anamnesia antes que de la rememoración histórica.

Los conservadores y los restauradores de películas, los historia dores del cine son facultativos del valor histórico. Por el contrario, el público ("el hombre moderno" según Riegl) recibe un des tino desviado de las películas porque en una filmoteca ya no son portadores de su destino inicial de ocio y, por ello, se convierten en inmemoriales. Como los monumentos reciclados desde el punto de vista patrimonial para el turismo cultural, las películas están desafectadas. En el concepto de desafectado, existe un afecto. El patrimonio, una etapa nueva en el alejamiento del des tino inicial de las películas y cuyo horizonte es la conservación, induce fatalmente ese desobramiento.

En relación con el objeto sagrado o de culto que se convierte en obra de arte en el museo, la película conoce sin duda una menor metamorfosis patrimonial gracias a la proyección, que es un fenómeno de abolición del tiempo y de reconstrucción de otro tiempo casi onírico, un presente de la obra constantemente reiniciada.

Sin embargo, podemos contar cuatro aspectos que marcan la película como objeto patrimonial: la proyección única en una fit
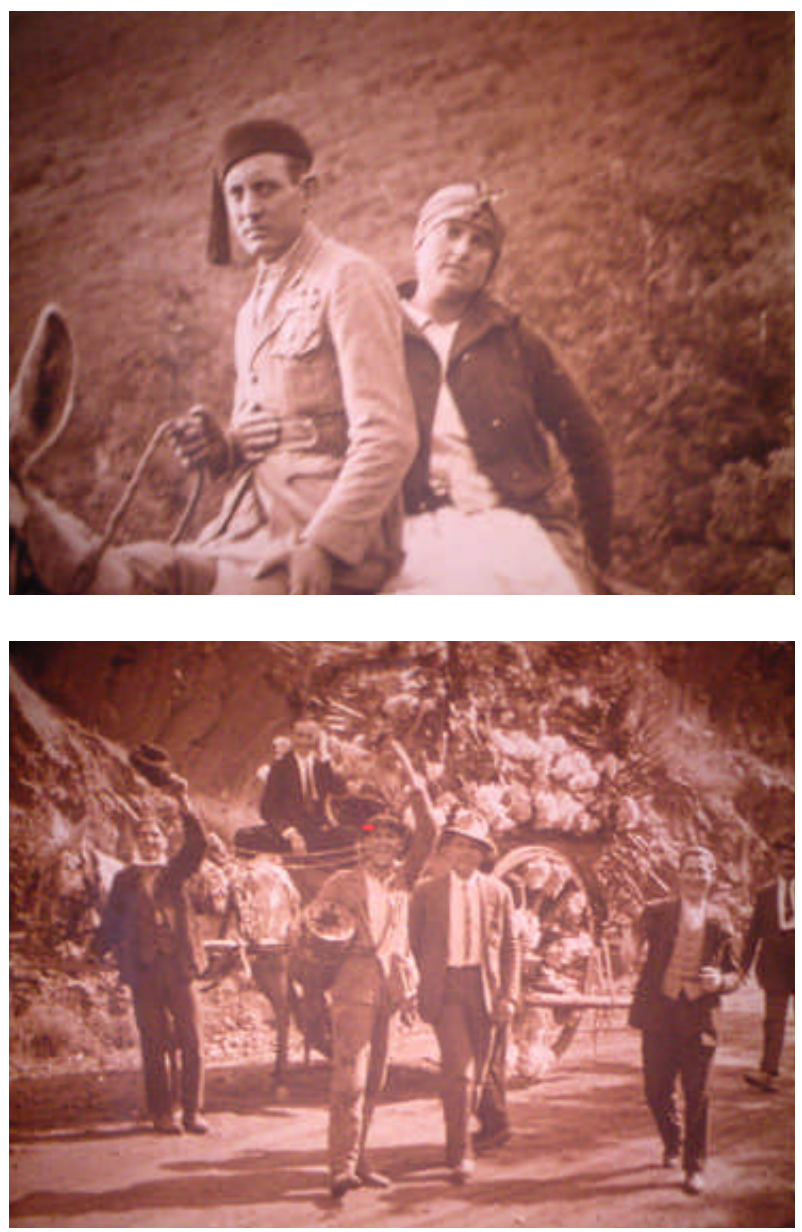

moteca, la inserción en la retrospectiva monográfica de su autor, la programación y el rumor pedagógico, la percepción de la fit moteca como un lugar de memoria del cine.

La noción de patrimonio cinematográfico no resulta por lo tanto evidente. Es un proceso complejo que ha conocido cuatro mutaciones. La primera fue la del cine mudo al sonoro. En los cinco primeros años de los años treinta, las filmotecas se crean para preservar el cine mudo. Es la primera toma de conciencia de una pérdida, la del cine mudo. La segunda mutación fue aquella que fue de la propiedad privada a la noción de museo del cine. Las películas son bienes corporales e incorporales, productos industriales comercializados que pertenecen a personas privadas 0 a monopolios capitalistas provenientes de la economía liberal (los que tienen derechos). En sesenta años, las películas han pasado de este sector privado, que descansa sobre el efímero comercial, al servicio público fuera de las urgencias de la producción, es 

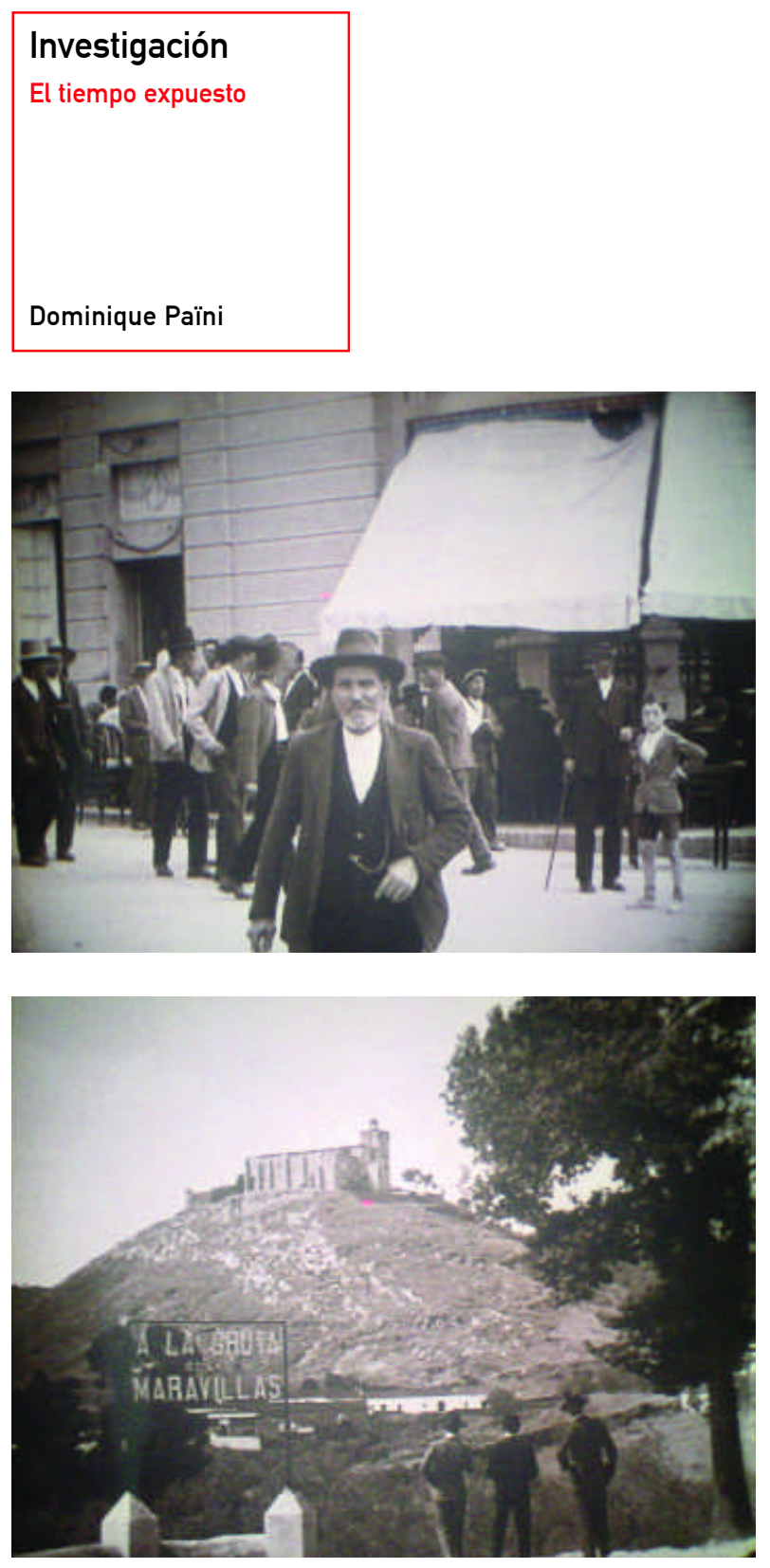

decir, el servicio ofrecido por las filmotecas cuya misión enciclopédica escapa al tiempo económico para alcanzar un tiempo simbólico. La tercera mutación es la de lo antiguo a lo moderno. En efecto, las filmotecas favorecen el control intelectual y la visión sintética del encadenamiento histórico, proponiendo una periodización, así pues una historia del arte cinematográfico: el cine mudo hasta 1930, el cine clásico sonoro de 1930 a 1945, el cine moderno de 1945 hasta hoy en día (de este último, habría que distinguir el cine contemporáneo, bastante comparable al que denominamos arte contemporáneo...). El cine moderno es aquél que toma prestadas, deliberadamente de las filmotecas, referencias estilísticas. El cine moderno consagra, pues, las fit motecas como museos de cine que ofrecen modelos del pasado a los nuevos cineastas. Picasso aprendió pintura en el Louvre, Godard aprendió cine en Langlois.

La última mutación es la de la industria al arte. La película que es, antes que nada, un objeto industrial, pasa a ser objeto de arte, obra, porque se conserva y se exhibe en las filmotecas, los museos del cine. Las filmotecas se convierten entonces en los primeros museos modernos, los más adaptados y reveladores del siglo XX, ecos de lo que mostraron ciertos artistas tales como Marcel Duchamp o Francis Picabia: es la institución museística que genera el valor artístico al imponer el valor de antigüedad y el valor de exposición.

Los años treinta fueron cruciales en Francia con la aparición sobre la colina de Chaillot del Musée des Monuments français (Museo de los monumentos franceses) y del Musée de l'Homme (Museo del Hombre), y a continuación la construcción del Musée des Arts et Traditions Populaires de G.H. Rivière (Museo de las Artes y las Tradiciones Populares de Georges Henri Rivière). La fit moteca francesa de Henri Langlois finalizó este movimiento. El fin de la tradición oral, el fin del terruño, la industrialización, permitieron estos museos.

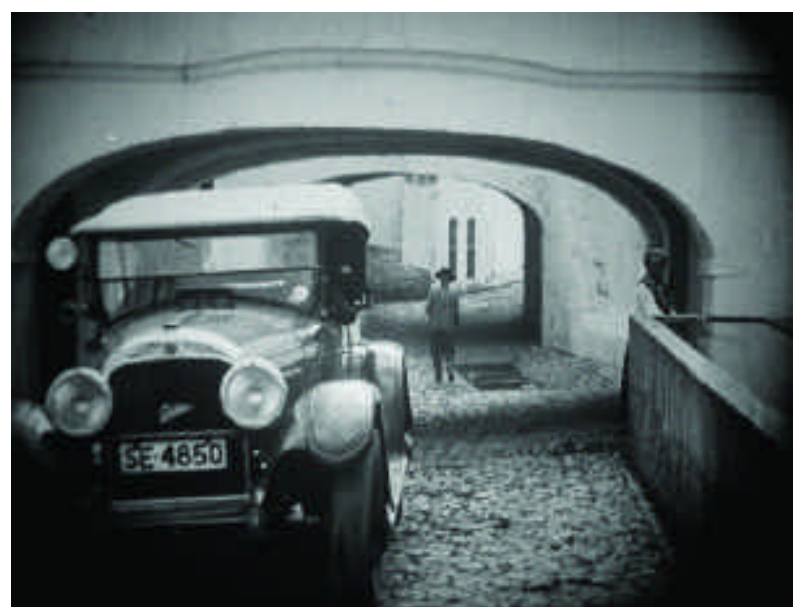

Es el descubrimiento de la posibilidad de traducir racionalmente -con el desarrollo de la etnografía y de la sociología- los mundos y las épocas, los unos cruzados con los otros. Es la afirmación de la comunicación que encierra entre paréntesis la singularidad de cada época y de cada mundo.

En esta comunicación generalizada que cierra Internet, ¿cuáles son las consecuencias de la reproducción videográfica y digital, una acción no despreciable de la política patrimonial en materia de arte del cine? Reproducir es una interpretación. Y ello perdura desde las primeras empresas romanas sobre la estatuaría helenística, hasta la reproducción de una película sobre una banda magnética o un DVD. Este paso de la proyección a la consulta ilimitada conlleva variaciones interpretativas (no se ve la misma película según se proyecta o se consulta: paradas sobre imagen, ralentí...). El espectador pasa de la hipnosis a la accesibilidad. 
Se trata, pues, de un proceso normal. Se conoció primero la Antigüedad mediante la escritura, luego por la réplica, finalmen te por la fotografía. La memoria del cine fue también durante mucho tiempo rescatada por la escritura (la fotografía fue complementaria), relegada hoy en día por el vídeo y la conservación digital. Esta última reproducción es menos metafórica que la fotografía en relación con la escultura. La videografía sólo es, evi dentemente, una reducción de la película, una réplica, fuera de su ámbito, la sala de proyección. Si la cinta de vídeo (o el DVD) no aprueba las condiciones espectatoriales de la película, ésta elude sin embargo ciertos efectos de ennoblecimiento patrimonial. Vuelve a colocar películas en el circuito económico. Representa igualmente una incontestable conservación, una prolongación de la memoria de las películas pero en condiciones más impuras que en una filmoteca. Dicho esto, las reproducciones de las películas recobran algo del origen industrial y comercial del cine, traicionando a su vez una de sus condiciones iniciales de nacimiento y de finalidad: la proyección.

Con las cadenas de televisión temáticas, todo aumenta de valor Antaño, sólo las películas llamadas de prime time se vendian caras. Hoy en día, la difusión de las películas se hace de manera ininterrumpida. Son necesarias películas durante todo el periodo de la difusión para justificar la película llamada de prime time. Una película de Henri Decoin olvidada se revaloriza respecto a las incombustibles películas de Gérard Oury o al reciente título del Silencio de los corderos. Una película de Decoin alcanza de pronto el rango de película de vigilancia, del mismo modo que se habla de una cámara. Ocupa el espacio de una programación, eventualmente poco frecuentada, pero que podría serlo. Como cámaras que vigilan territorios sin habitantes, algunas películas vigilan la parrilla de programación sin espectadores. Esta soledad programática se paga de ahora en adelante. El patrimonio cinematográfico se convierte así en una cultura de vigilancia, una imaginería de vigilia, un stand-by programático. Pero por ello, está disponible a la grabación del vídeo, mirada delegada a una máquina grabadora, esa hucha, esa media de seda del jubilado amante del cine que atesora un patrimonio cinematográfico.

Dicho esto, la noción de patrimonio cinematográfico da lugar a numerosas tonterias con apariencias cientificas. La histeria ligada a la conservación de películas sobre su antiguo soporte llamado nitrato es un ejemplo palpable. Se confunden habitualmente los efectos retinianos reales de un material cinematográfico y el gusto o el estilo plástico de una época.

\section{El nitrato no existe}

En junio de 2000 en el Congreso de la Federación Internacional de los Archivos de Películas, Paris-Londres, un cortometraje rea- lizado por Aubrey Arroy en 1930 y restaurado por la Filmoteca francesa, proporciona una experiencia edificante.

Esta copia había sido sacada de un nitrato positivo y no de un negativo. Se había realizado por lo tanto un internegativo y luego un nuevo positivo a partir de ese internegativo. En realidad se proyectó una imagen única constituida de dos películas. La parte derecha y la parte izquierda de la imagen proyectada no provenían de la misma película: en un proyector estaba el antiguo nitrato positivo conservado y sobre el otro proyector se utilizaba la nueva copia de acetato. Un pequeño juego de acertijo residía en la distinción de las dos imágenes proyectadas ¿Los archiveros reunidos, en su mayoría adoradores del nitrato, serian capaces de reconocer el nitrato proyectado? Pues eso era, en realidad, lo fundamental para ellos, tal era su apego en restituir un valor de antigüedad a la obra de la pelicula. Esta especie de prueba era importante por el hecho de que deben ofrecer a la visión del público contemporáneo el mejor material, es decir, reconstituir el mejor valor de exposición posible para la película. Por supuesto, nadie pudo distinguir esos dos materiales durante la proyección, incluidos los amantes del nitrato. Pero entonces, ¿existe el nitrato? ¿Una naturaleza singular de la imagen se adhiere a la película de nitrato de celulosa? ¿Qué añoramos realmente cuando añoramos el nitrato?

Los años treinta constituyen una belle époque, años que podían conocer la confusión entre una película publicitaria de uso industrial y comercial y la búsqueda de las vanguardias. Es el caso de Paris-Londres. No podemos imaginar hoy en día una confusión comparable entre un clip de pub y una película experimental.

Pero entonces, ¿qué emocionaba tanto? ¿qué seducia tanto? ¿qué es lo que producia esa febrilidad lírica cuando los archiveros del film hablaban del nitrato? ¿Acaso era ese rollo de película y los supuestos efectos especificos jamás verdaderamente descritos ni definidos? ¿0 entonces ese constructivismo plástico de los encuadres y del movimiento, el ritmo del montaje, esa imagen "entrecortada" de los años treinta de la que habla Walter Benjamin? ¿La belleza de los contrastes luminosos resultaría de la materia-película que los grabó o acaso fue el gusto visual dominante de una época que arquitecturaba la representación del mundo según una concepción ordenada y dinámica, privilegiando el brillo de las nuevas materias (vidrio y acero) y el ángulo derecho más que el arabesco del anterior Art Nouveau, a imagen y semejanza de una arquitectura neoplástica?

Digámoslo claramente: el nitrato no está en el rollo de la película; está en el ojo. Si el gusto constructivista volviese hoy -y de una cierta manera ha vuelto bajo la forma declamativa del postmodernismo en los años ochenta- el rollo de la película de acetato podría restituir, si quisiéramos, lo que amamos y lo que fascina en la dulzura singular de los contornos, en la luz asustadiza, el esfumato de las imágenes grabadas sobre el soporte de nitrato. 


\section{Investigación}

El tiempo expuesto

Dominique Païni

Además, no es únicamente el rollo de la película lo que ha cambiado desde los años del nitrato. Es igualmente el maquillaje de los actores y de las actrices. En los años treinta, estos últimos eran maquillados con polvos más que con cremas. Existe probablemente una relación entre el terciopelo de la piel de una actriz, esa superficie de melocotón, ese efecto luminoso y coloreado considerado como perdido y que ofrecía la imagen de una copia de nitrato.

Por lo tanto, ¿de qué estamos hablando? ¿Una materia pelicular desaparecida o un maquillaje que no se practica más? ¿Un rollo de película que añoramos o una piel femenina de la que sentimos la nostalgia erótica de la desaparición en la representación dominante de la mujer? ¿El grano de la película ha reemplazado hoy en día ese tipo de encarnado? Una cierta pulverulencia de la materia imagen de los años veinte y treinta -el empolvamiento de las epidermis de las actrices (iy de los actores!)- ha pasado en las películas de alta sensibilidad cuyo grano creciente graba de ahora en adelante las caras pintadas y no empolvadas.

¡Se proyecta sobre el nitrato a falta de poder seguir proyectándolo! ¿Amenazado de desaparición, inflamable, peligroso? ¡Cierto! Todo eso es verdad. Pero en ese retorno al nitrato que las filmotecas viven, hay que percibir sobre todo un imaginario bastante banal, una nostalgia de las ruinas.

Este imaginario es también comunitario: el material químico que soporta la imagen tiende a ser más importante que la expresión artística. Se crearía así un consenso, un acuerdo sacado de un material, por añadidura casi desaparecido o en vía de serlo, más que la eterna fractura, la infinita diversidad subjetiva llevada al arte de la película que revela las oposiciones de gusto. En suma, una objetividad "cientificista" contra el enfrentamiento de los puntos de vista estéticos. Tres valores se han sucedido para jus tificar la acción de los archiveros de películas a lo largo de los años sesenta.

Cuando se crearon las primeras filmotecas, fue el valor estético el que primó para imponer el arte del cine en el seno de las demás artes: el Séptimo Arte. Luego, el valor documental, la fuerza del testimonio y la grabación de la vida en beneficio de la memoria de las generaciones venideras se privilegiaron entre las razones de conservar las películas.

Esto constituyó a los ojos de los conservadores la virtud sociológica-histórica del cine a partir de los años sesenta. Finalmente, el valor material del cine parecía prevalecer a partir de ahora sobre las dos primeras: el nitrato frágil y el peligroso, precioso y despreciado por los tecnócratas y los mercaderes, confiere un valor, un valor anticuario para todo el cine grabado sobre ese soporte obsoleto, y ello le dota de un atractivo patrimonial. Dicho de otra manera: la dimensión química dispensa disfrutar el cine eligiendo, jerarquizando, anticipando el gusto. Se trata finalmente de un retraimiento positivista sostenido por un pensamiento.

Esta actitud no es un fenómeno nuevo en la historia de las artes, ya que esta historia está hecha de sustituciones de soportes sobre los cuales se encarna la obra de arte. La pintura no se ha apagado cuando los pintores dejaron de moler sus pigmentos y sus óxidos o cuando los paneles de madera fueron reemplazados por el soporte textil. Desde siempre las imágenes han cambiado y han variado infinitamente sus soportes. El arte no está, pues, sólo hecho de memoria. Está igualmente hecho de pérdida, de olvido, de melancolía de esta pérdida y la invención de nuevas formas compensa por una parte, cumple el duelo de lo que se abandona, se destruye, se olvida y se reemplaza. La pérdida permite el nuevo arte. Es igualmente verdad para el legendario nitrato.

¿Podemos esperar encontrar las virtudes del nitrato de la misma manera que la proyección desde un disco-vídeo reduce actualmente su diferencia de calidad con respecto a la imagen pelicular proyectada? Estas divergencias y sus diferencias son también aquéllas que los hombres toleran. Puesto que si la decepción está a veces justificada en lo que se refiere a una salvaguardia realizada por trascripción sobre soporte de acetato llamado de seguridad, ello es fruto tanto del gusto de los conservadores y de los técnicos en los laboratorios como de la calidad del soporte.

Tomemos un ejemplo en otro ámbito. Las tres batallas de Ucello -en Londres, en Florencia, en París- se restauraron de forma muy diferente aunque pertenecian a un mismo conjunto. Viva y warholiana en Londres, Iuminosamente tierna en Florencia, sombría y nocturna en París. Cada una de esas preservaciones parece traducir la cultura plástica de los tres universos culturales. Los gustos de los restauradores y el valor que confieren a las marcas del pasado están probablemente cercanos pero están marcados por la cultura nacional y por la época de la intervención restauradora.

La película Vértigo de Alfred Hitchcock fue retirada y restaurada (como todo el mundo dice de forma trivial hoy en día cuando en realidad se trata simplemente, en la mayoría de los casos, de una nueva tirada de nuevas copias). No podemos creer que sea la naturaleza del rollo de la película utilizada la que explique la diferencia respecto a las copias de época, su deslumbrante piqué, su color pastel tan dieciochesco, el liso tan perfecto de la cara de Kim Novak. En las nuevas tiradas, las imágenes parecen que estuviesen cubiertas de polvo. Acaso corresponden al gusto de una época, la nuestra, familiar de las películas de John Cassavetes y de Wong Kar-Waï: rollos de películas ultrasensibles utilizadas sin iluminación y por lo tanto de grano espeso. El gusto cambia, lo aceptable evoluciona y no solamente las virtudes quí 


\section{Información}

Filmotecas europeas

micas de la película. Sin embargo se pueden reproducir exactamente los efectos visuales de las copias de origen de Vértigo si se toma dicha decisión.

Obviamente, hay que guardarlo todo, guardar las copias de nitrato ¿Pero acaso se persigue el mostrarlas obligatoriamente o venerarlas como reliquias?

Esta conservación es indispensable para concebir nuevas tiradas fieles a las copias de época cada veinte o treinta años, cuando el acetato pierde sus cualidades de conservación. Y esta reproducción no busca volver a ver el cine como en el pasado ya que nunca conoceremos éste. 0 entonces, habría que reconstituirlo todo, incluido la iluminación de carbón de los proyectores cuya luz era más caliente que la del xenón ¿Qué opinar igualmente de las pantallas que interceptan el haz luminoso?, ¿y qué decir de la arquitectura de las salas?

Durante ese simposio, mucha moral se mezcló con la nostalgia (jel nitrato era mejor!). La idea dominante no era sin embargo el peligro de perder el nitrato. Era la extraña voluntad de engalanarlo con todas las virtudes ¿Quizás inconscientemente su apego sea porque es un material que arde espectacularmente es explosivo y nublado? ¿0 se añora el nitrato más por su color que su olor? ¿Y quizás porque permite ver "las maravillosas nubes" de Baudelaire?

Añorar el nitrato se identifica a una voluntad de revivir lo pasado, lo que supone de abolición del tiempo, de actualización del pasado. Es lo que llamamos el gusto kitsch al que estamos tan sen sibles en el transcurso de este cambio de milenio y que se parece a veces al lamento del resentimiento.

\section{Nota}

Este artículo recopila algunos fragmentos del volumen Le Temps Exposé (PAïNI, D. Editions Cahiers du Cinéma, 2002). La traducción del francés ha sido realizada por ITC.

\section{Albania}

Albanian Film Archive

\section{Alemania}

Bundesarchiv - Filmarchiv: www.bundesarchiv.de

Deutschen Filminstituts - Filmarchiv: www.filminstitut.de

\section{Armenia}

Armenian National Cinematheque

\section{Austria}

Film Archiv Austria: www.filmarchiv.at

\section{Bélgica}

Cinematheque Royale de Belgique: www.ledoux.be

\section{Bielorrusia}

The Belarusian State Archive of Films, Photographs and Sound Recordings: archives.gov.by/EArh/Erx_dzerginsk.htm

\section{Croacia}

Croatian State Archives - Croatian Film Archives: www.arhiv.hr

\section{Dinamarca}

Danish Film Institute - Film Archive: www.dfi.dk

\section{Eslovaquia}

Slovak Film Institute: www.sfu.sk

\section{Eslovenia}

Slovenska Kinoteka: www.kinoteka.si

\section{Estonia}

Estonian Film Archives: www.filmi.arhiiv.ee

\section{Finlandia}

Finnish Film Archive: www.sea.fi

\section{Francia}

Centre National de la Cinématographie (CNC)-Cinémathèque française: www.cnc.fr ; www.cinemathequefrancaise.com

Grecia

Greek Film Center - Greek Film Archive: www.gfc.gr

\section{Hungría}

Hungarian National Film Archive: www.filmintezet.hu

Irlanda

Irish Film Archive: www.fii.ie/archive 